\title{
EFFECTS OF CAERULEIN ON INTESTINAL TRACT AND GALLBLADDER
}

\author{
Nobuo NAKAMURA, Yoshihisa KOYAMA, Tetsuo KOJIMA \\ and Hiroshi TAKAHIRA \\ Fuji Research Laboratory, Kyowa Hakko Kogyo Co., Ltd., \\ Nagaizumi, Sunto, Shizuoka, Japan
}

Accepted 4 September 1972

\begin{abstract}
Caerulein produces an acceleration of motility of rabbit ileum (in situ). The effect appears to be based on peripheral action. Sympathetic nerve endings appear not to be involved in the action. In the small intestine transit test (mouse) caerulein accelerated the transit when carbon powder was present. It is therefore considered that caerulein does not induce generalized muscle contraction but rather a coordinated propulsion in the intestinal tract. Caerulein in a larger dose discontinues flow of content out of the stomach probably due to pyloric spasm.

Caerulein produced contraction of rabbit gallbladder (in situ) at doses lower than the threshold dose of ileum motility acceleration.

In isolated ileum of guinea-pig, caerulein produced contraction at low doses. The action of caerulein appears to be mediated through the nerve: it appears to act on non-nicotinic receptor of the cholinergic nervous element and accelerate liberation of acetylcholine. It also appears to act, at least in part, on the atropine-resistant nervous element.

In isolated guinea-pig gallbladder, as different from the in situ case, caerulein produced contraction at doses almost equal to the threshold of contraction in isolated guinea-pig ileum. The action of caerulein appears to be a direct action on the gallbladder smooth muscle.

Caerulein had no effect on isolated vas deferens and uterus. For this reason, the action of caerulein is considered to be of organ specificity.
\end{abstract}

Caerulein is a decapeptide which was extracted from the skin of Australian Hyla caerulea by Anastasi, Erspamer and Endean in 1967 (1). Amino acid composition and sequence of caerulein are shown in the following structure.

Chemical structures

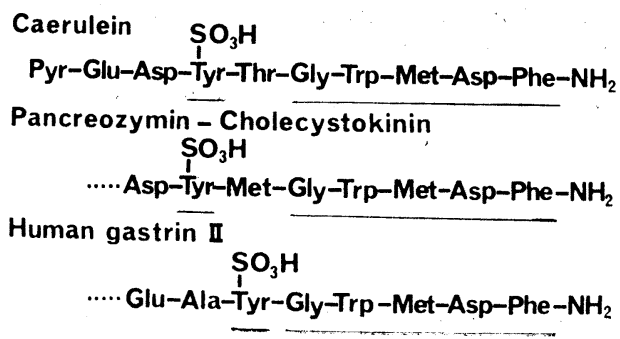


Caerulein as well as pancreozymin-cholecystokinin and human gastrin II has a Cterminal pentapeptide and tyrosil sulfate. Caerulein shows activity correlated in structure with gastrointestinal hormones, and has various pharmacological actions such as contraction of the gallbladder, acceleration of motility of the intestinal tract, pancreatic secretion, gastric secretion and hepatic bile secretion etc. Actions of caerulein on motility of the ileum and the gallbladder of dog in situ and the mechanism of actions on isolated intestinal tract and gallbladder of rabbit and guinea-pig have been already reported (2-7).

In this paper, actions of caerulein on the following subjects were investigated:

1) Actions on motility of the intestinal tract and the gallbladder of rabbit (in situ) and possible mechanisms in these organs.

2) Action on transit in the small intestine of mouse.

3) Detailed mechanism of actions on the isolated ileum and gallbladder of guineapig.

4) Actions on other smooth muscles such as the vas deferens and the uterus.

\section{METHODS}

1. Motility of the ileum and the gallbladder in situ

Male rabbits weighing $2.0-2.6 \mathrm{~kg}$ and anesthetized with urethane $(1 \mathrm{~g} / \mathrm{kg}$, i.p.) were used. They were fasted for $24 \mathrm{hr}$ before experiment. After laparotomy, a vinyl tube (diameter $1 \mathrm{~mm}$ ) filled with physiological saline was cannulated into the gallbladder and a small rubber balloon was filled with water $(5 \mathrm{ml})$ and gently inserted into the ileum. These were connected to a water manometer and a pressure transducer. Intraluminar pressure of the gallbladder and the ileum was registered on the polygraph (Nihon Koden RM-85). Carotid artery pressure was simultaneously registered by a transducer for blood pressure (Nihon Koden MPU-0.5-290).

In addition, bilaterally vagotomized (at the level of the neck) and splanchnicotomized rabbits, and also reserpinized (reserpine $2.5 \mathrm{mg} / \mathrm{kg}$ had been injected s.c. $24 \mathrm{hr}$ previously) and bilaterally adrenalectomized rabbits were used.

\section{Test of transit in the small intestine}

Mice (male dd-mice, $20 \pm 2 \mathrm{~g}$ ) were fasted for $17-20 \mathrm{hr}$. $0.1 \mathrm{ml} / 10 \mathrm{~g}$ of carbon powder solution, containing $0.5 \%$ of carbon powder and $1 \%$ of carboxymethylcellulose, was orally administered. After $20 \mathrm{~min}$, digestive organs were isolated and rapidly transferred to ice. Motility of digestive organs was stopped and the digestive tract was stretched. Transit rate of carbon powder was calculated by the following formula.

Transit rate $(\%)=\left[\frac{\text { distance from the cardia of the stomach to carbon powder }}{\text { distance from the cardia of the stomach to the cecum }}\right] \times 100$

Caerulein was injected i.v., s.c. or i.p. $10 \mathrm{~min}$ before and after oral administration of carbon powder.

3. Isolated organs

1) Ileum

Segments of the ileum isolated from male guinea-pigs (300-400 g) and male rabbits 
$(2.0-2.5 \mathrm{~kg})$ were suspended in a $10 \mathrm{ml}$ organ bath filled with Tyrode solution at $32 \pm 1{ }^{\circ} \mathrm{C}$ and gassed with air. Tyrode solution used herein contained $8.0 \mathrm{~g}$ of $\mathrm{NaCl}, 0.2 \mathrm{~g}$ of $\mathrm{KCl}$, $0.2 \mathrm{~g}$ of $\mathrm{CaCl}_{2}, 0.113 \mathrm{~g}$ of $\mathrm{MgCl}_{2}, 0.049 \mathrm{~g}$ of $\mathrm{NaH}_{2} \mathrm{PO}_{4}, 1.0 \mathrm{~g}$ of $\mathrm{NaHCO}_{3}$ and $1.0 \mathrm{~g}$ of glucose to a liter. Responses of the preparations to drugs were recorded on a running drum through an isotonic lever. Caerulein was administered at a dose level of $10^{-9} \mathrm{~g} / \mathrm{ml}$, which showed $50-75 \%$ of maximum contraction at intervals of at least $15 \mathrm{~min}$. Various antagonists were administered $10 \mathrm{~min}$ before caerulein.

\section{Coaxial stimulation of the ileum}

Electrical stimulation of the ileum from guinea-pigs was carried out according to the methods described by Paton (8), Takagi and Takayanagi (9). Rectangular current pulses of $1 \mathrm{msec}$ duration and of sufficient strength to produce a moderate contraction with a single shock were applied to the electrode; the intraluminal electrode being used as the anode.

\section{2) Gallbladder}

The gallbladder was isolated from male guinea-pigs (300-400 g). Contraction 15 min after the administration of caerulein was measured according to the method described in the experiments on the ileum. Krebs solution kept at $32 \pm 1{ }^{\circ} \mathrm{C}$ was used as a bath fluid. Krebs solution used herein contained $6.9 \mathrm{~g}$ of $\mathrm{NaCl}, 0.39 \mathrm{~g}$ of $\mathrm{KCl}, 0.5 \mathrm{~g}$ of $\mathrm{CaCl}_{2}, 0.16 \mathrm{~g}$ of $\mathrm{NaH}_{2} \mathrm{PO}_{4}, 0.29 \mathrm{~g}$ of $\mathrm{MgSO}_{4}, 2.1 \mathrm{~g}$ of $\mathrm{NaHCO}_{3}$ and $1 \mathrm{~g}$ of glucose in a liter.

3) Vas deferens

The vas deferens was isolated from male guinea-pigs (300-400 g). Direct action and anti-adrenaline action were observed according to the method described in the experiments on the ileum.

\section{4) Uterus}

Rats were examined by vaginal smears and were utilized during natural oestrus or diestrus stage. To ensure oestrus stage, some rats were given oestradiol benzoate ( 50 /g/ $/ \mathrm{kg}$ i.p.) 24 to $48 \mathrm{hr}$ before experiments. One horn of the uterus was isolated from rat. Direct action, anti-oxytocin action and effect on spontaneous motility were observed according to the method described in the experiments on the ileum. Modified Locke-Ringer solution described by Kumagai et al. (10) was used as a bath fluid. The temperature of bath was $28 \pm 1{ }^{\circ} \mathrm{C}$. For the observation of spontaneous motility, Modified Locke-Ringer solution in which the amount of $\mathrm{CaCl}_{2}$ had been increased five-fold was used as a bath fluid.

Drugs: caerulein (FI 6934), acetylcholine chloride, nicotine acid tartrate, 5-hydroxytryptamine creatinine sulfate, histamine dihydrochloride, atropine sulfate, eserine sulfate, hexamethonium bromide, tetrodotoxin, morphine hydrochloride, diphenhydramine hydrochloride, cyproheptadine hydrochloride, propranolol hydrochloride, phentolamine mesylate.

\section{RESULTS}

1. Effects on motility of the intestinal tract and the gallbladder in situ Intravenous injection of caerulein produced an acceleration of motility of rabbit ileum 
after a short latent period. No noticeable change was observed in the frequency of peristaltic waves while an increase in the amplitude and the tone was observed. The threshold dose was approx. $10 \mathrm{ng} / \mathrm{kg}$. As the dose levels were increased, an increase in the amplitude and the tone was intensified and a prolongation in the effect was more evident (Fig. 1). Response to s.c. injection of caerulein began after 3-5 min. The threshold dose was approx. $0.5 \mu \mathrm{g} / \mathrm{kg}$.

Caerulein produced a contraction of rabbit gallbladder which began immediately following an i.v. injection of caerulein (Fig. 1). The threshold dose ranged from 1 to $5 \mathrm{ng} / \mathrm{kg}$. As the dose level was increased, the contraction was stronger and the duration longer. Tachyphylaxis and sensitization were not present.

With reference to the effect on blood pressure, an i.v. injection of $10 \mathrm{ng} / \mathrm{kg}$ of caerulein resulted in an immediate decrease in blood pressure in most cases while little change was observed with a s.c. injection of $0.5 \cdot \mu \mathrm{g} / \mathrm{kg}$.

In experiments where bilaterally vagotomized, splanchnicotomized rabbits and reserpinized, bilaterally adrenalectomized rabbits were used, the i.v. injection of caerulein produced an acceleration of motility of the ileum at a dose of approx. $10 \mathrm{ng} / \mathrm{kg}$ (Figs. 2 and 3) and contraction of the gallbladder at a dose ranging from 1 to $5 \mathrm{ng} / \mathrm{kg}$. Therefore, the threshold doses were almost similar to those in intact rabbits.

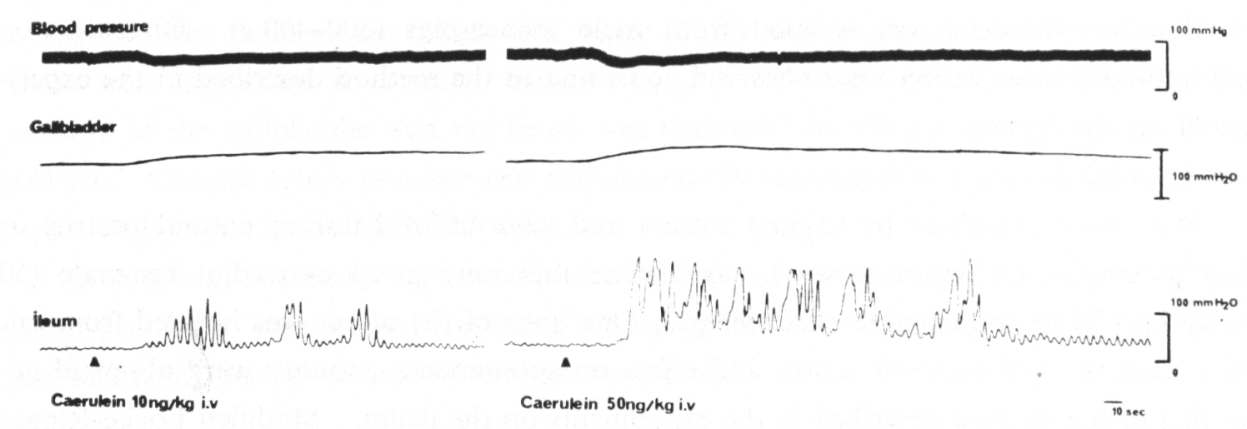

FIG. 1. Effect of caerulein on motility of ileum and gallbladder in anaesthetized rabbits.
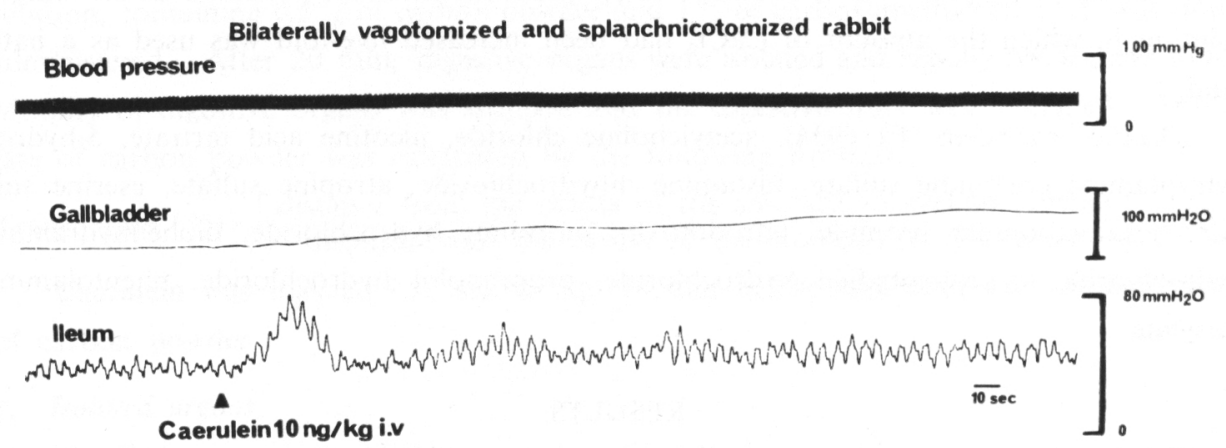

FIG. 2. Effects of caerulein on motility of ileum and gallbladder in bilaterally vagotomized and splanchnicotomized rabbits. 
Reserpinized and bilaterally adrenalectomized rabbits

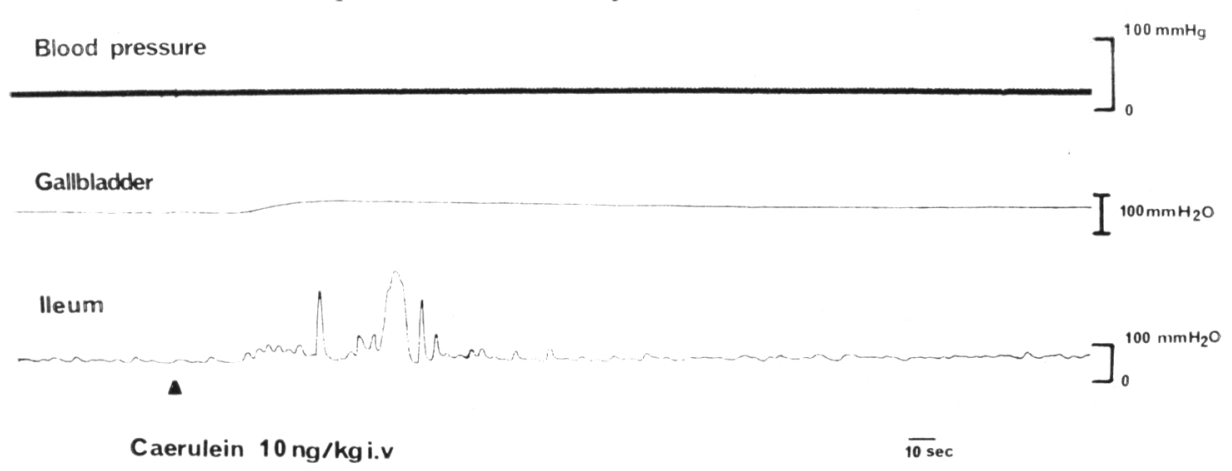

FIG. 3. Effects of caerulein on motility of ileum and gallbladder in reserpinized and bilaterally adrenalectomized rabbits.

\section{Transit in the small intestine}

Caerulein was administered i.v., s.c. or i.p. $10 \mathrm{~min}$ before the administration of carbon powder. Transit rate was promoted in small doses regardless of the route of the admin-

TABLE 1. Effect of caerulein on transit rate of carbon powder in the small intestine (mouse).

Caerulein injected i.v., s.c. or i.p. $10 \mathrm{~min}$ before and after oral administration of carbon powder.

i.v.

\begin{tabular}{|c|c|c|}
\hline & $10 \mathrm{~min}$ before & $10 \mathrm{~min}$ after \\
\hline Control (Saline) & $53.5 \pm 4.2$ & $60.5+3.7$ \\
\hline Caerulein $0.1 \mu \mathrm{g} / \mathrm{kg}$ & $61.7 \div 2.9$ & $66.0 \pm 3.5$ \\
\hline 1 & $58.0 \pm 4.9$ & $80.4+4.1^{*}$ \\
\hline " 10 & $76.9 \pm 2.8$ & $84.6 \pm 5.7^{*}$ \\
\hline 50 & $22.1 \pm 10.8$ & $73.4 \pm 5.2$ \\
\hline \multicolumn{3}{|l|}{ s.c. } \\
\hline & $10 \mathrm{~min}$ kefore & 10 min after \\
\hline Control (Saline) & $61.7+3.7$ & $48.1+2.8$ \\
\hline Caerulein $1 \mu \mathrm{g} / \mathrm{kg}$ & $76.4+2.2^{*}$ & $75.5 \pm 3.8^{*}$ \\
\hline " 10 & $2.5 \pm 1.2^{*}$ & $78.1 \pm 7.0$ \\
\hline " 50 & $2.1 \pm 1.2^{*}$ & $77.8 \pm 4.2^{*}$ \\
\hline \multicolumn{3}{|l|}{ i.p. } \\
\hline & $10 \mathrm{~min}$ tefore & $10 \mathrm{~min}$ after \\
\hline Control (Saline) & $56.2+3.7$ & $44.3+4.8$ \\
\hline Caerulein $0.1 \mu \mathrm{g} / \mathrm{kg}$ & $83.4 \pm 4.4^{*}$ & $73.8 \pm 8.9$ \\
\hline " 1 & $88.9 \pm 2.6^{*}$ & $88.1 \pm 5.3^{*}$ \\
\hline " 10 & $44.9 \pm 14.1$ & $91.0 \pm 3.1^{*}$ \\
\hline " 50 & $3.8 \pm 1.8^{*}$ & $75.3 \pm 5.7^{*}$ \\
\hline
\end{tabular}

Values are means \pm standard errors. Each group included 10 mice.

* : significantly different from control $\mathrm{P}<0.01$ 


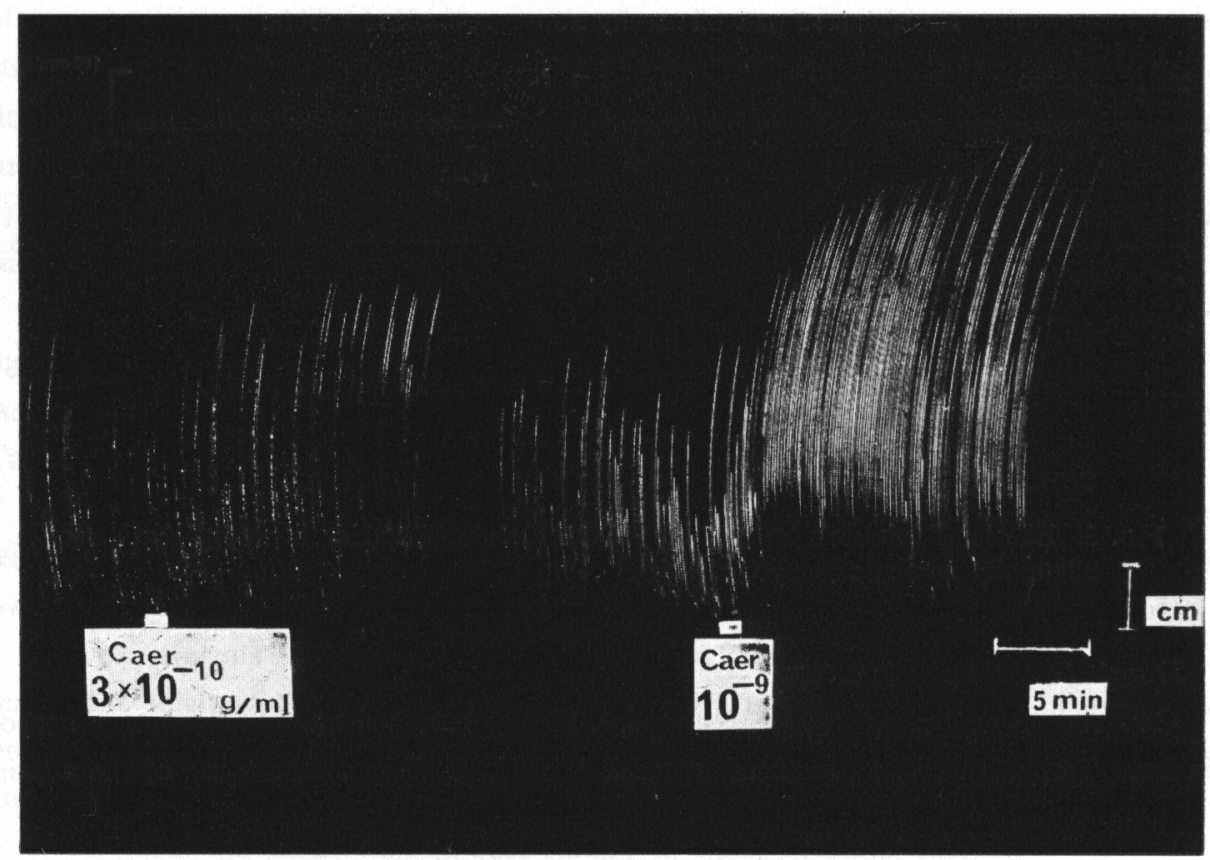

FIG. 4. Effect of caerulein on isolated ileum of rabbit. Caer : caerulein

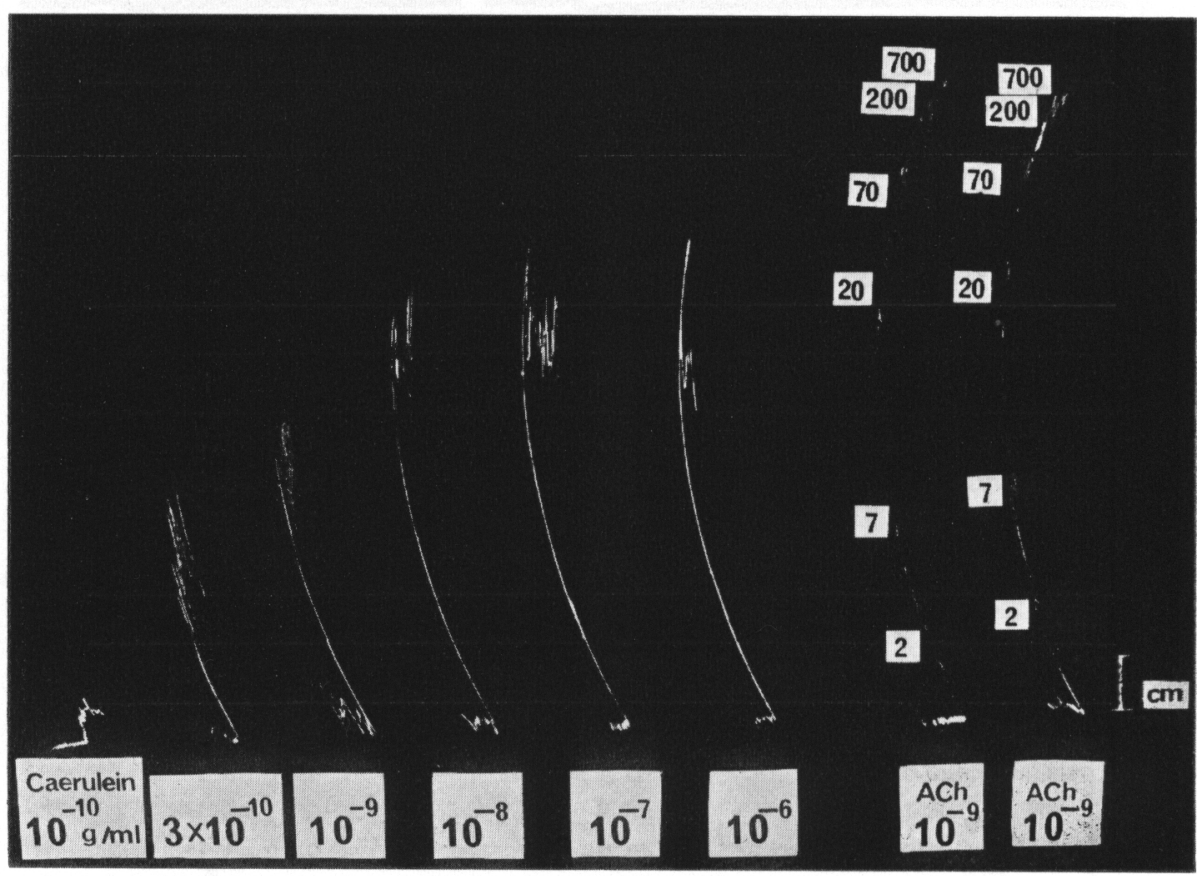

FIG. 5. Effects of caerulein and ACh on isolated ileum of guinea-pig. ACh : acetylcholine. 
istration of caerulein, but in large doses the rate was rather inhibited. Caerulein promoted transit rate $10 \mathrm{~min}$ after the administration of carbon powder. The rate was not inhibited even in large doses (Table 1).

\section{Isolated organs}

\section{1) Ileum}

Caerulein produced an acceleration of rhythmic movement after contraction of isolated rabbit and guinea-pig ileum (Figs. 4 and 5). The threshold dose was $10^{-10}-3 \times$ $10^{-10} \mathrm{~g} / \mathrm{ml}$. Tachyphylaxis and sensitization were not present but dose-response relationship was observed.

The maximum contraction of isolated guinea-pig ileum produced by caerulein was $70-80 \%$ of that by acetylcholine. $\mathrm{PD}_{2}$ value was found to be $9.28 \pm 0.17$ (mean \pm standard error of 5 experiments).

\section{Effect of antagonists on the contraction of isolated guinea-pig ileum by caerulein}

\section{Atropine}

The contraction of the ileum produced by caerulein was antagonized by atropine. Atropine $10^{-7} \mathrm{~g} / \mathrm{ml}$, which completely inhibited the contraction by acetylcholine, inhibited the contraction by caerulein by approx. $30 \%$ and the contraction by nicotine by approx. $60 \%$ (Fig. 6) (Table 2). The contraction produced by caerulein was not completely inhibited even when the dose of atropine was increased to $10^{-6} \mathrm{~g} / \mathrm{ml}$ (Table 2).

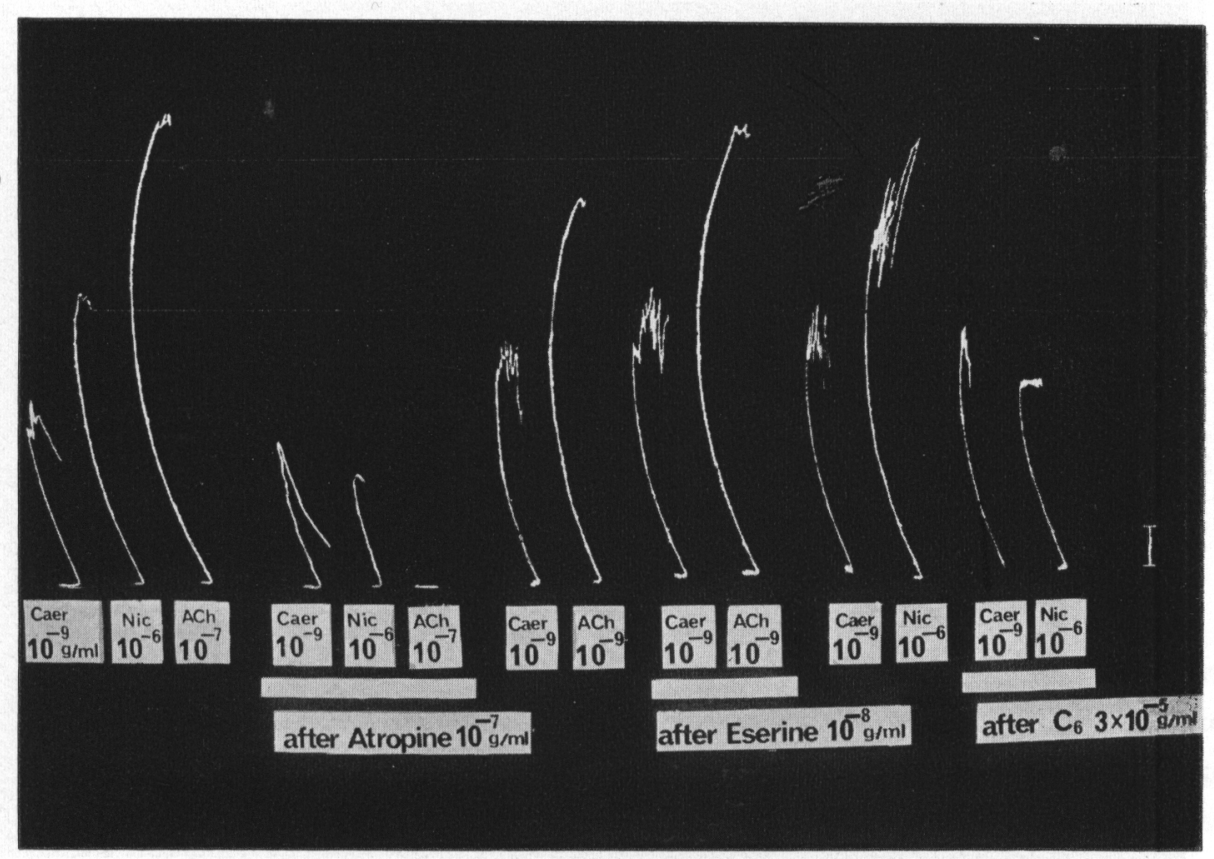

FIG. 6. Effects of atropine, eserine and $\mathrm{C}_{6}$ on contraction of guinea-pig ileum produced by caerulein, $\mathrm{ACh}$ and nicotine.

Caer : caerulein. ACh : acetylcholine. Nic : nicotine. 
TABLE 2. Effect of various antagonists on contraction of guinea-pig ileum by caerulein, nicotine and acetylcholine.

\begin{tabular}{llccc}
\hline & & \multicolumn{3}{c}{ Mean response \% as control } \\
\cline { 3 - 5 } & & $\begin{array}{c}\text { Caerulein } \\
10^{-9} \mathrm{~g} / \mathrm{ml}\end{array}$ & $\begin{array}{c}\text { Nicotine } \\
10^{-6} \mathrm{~g} / \mathrm{ml}\end{array}$ & $\begin{array}{c}\text { Acetylcholine } \\
10^{-7} \mathrm{~g} / \mathrm{ml}\end{array}$ \\
\hline Atropine & $10^{-7} \mathrm{~g} / \mathrm{ml}$ & 72.5 & 42.4 & 0 \\
\multicolumn{1}{c}{ " } & $10^{-6}$ & 51.0 & - & 0 \\
Eserine & $10^{-8}$ & 123.9 & - & $139.0^{*}$ \\
Hexamethonium & $3 \times 10^{-5}$ & 91.2 & 51.2 & - \\
Morphine & $10^{-6}$ & 4.2 & 21.8 & 96.7 \\
Tetrodotoxin & $10^{-7}$ & 0 & 3.2 & 99.0 \\
Nicotine & $10^{-5}$ & 0 & - & 98.5 \\
\hline
\end{tabular}

Each value is the mean of at least five experiments.

* : Acetylcholine $10^{-9} \mathrm{~g} / \mathrm{ml}$

\section{Eserine}

Eserine $10^{-8} \mathrm{~g} / \mathrm{ml}$, which by itself produced no contractions, potentiated the contraction by acetylcholine more intensively than that by caerulein (Fig. 6) (Table 2).

\section{Hexamethonium $\left(\mathrm{C}_{6}\right)$}

Hexamethonium $3 \times 10^{-5} \mathrm{~g} / \mathrm{ml}$ inhibited the contraction by nicotine $10^{-6} \mathrm{~g} / \mathrm{ml}$ by approx. $50 \%$, whereas the contraction by caerulein was only slightly influenced (Fig. 6) (Table 2).

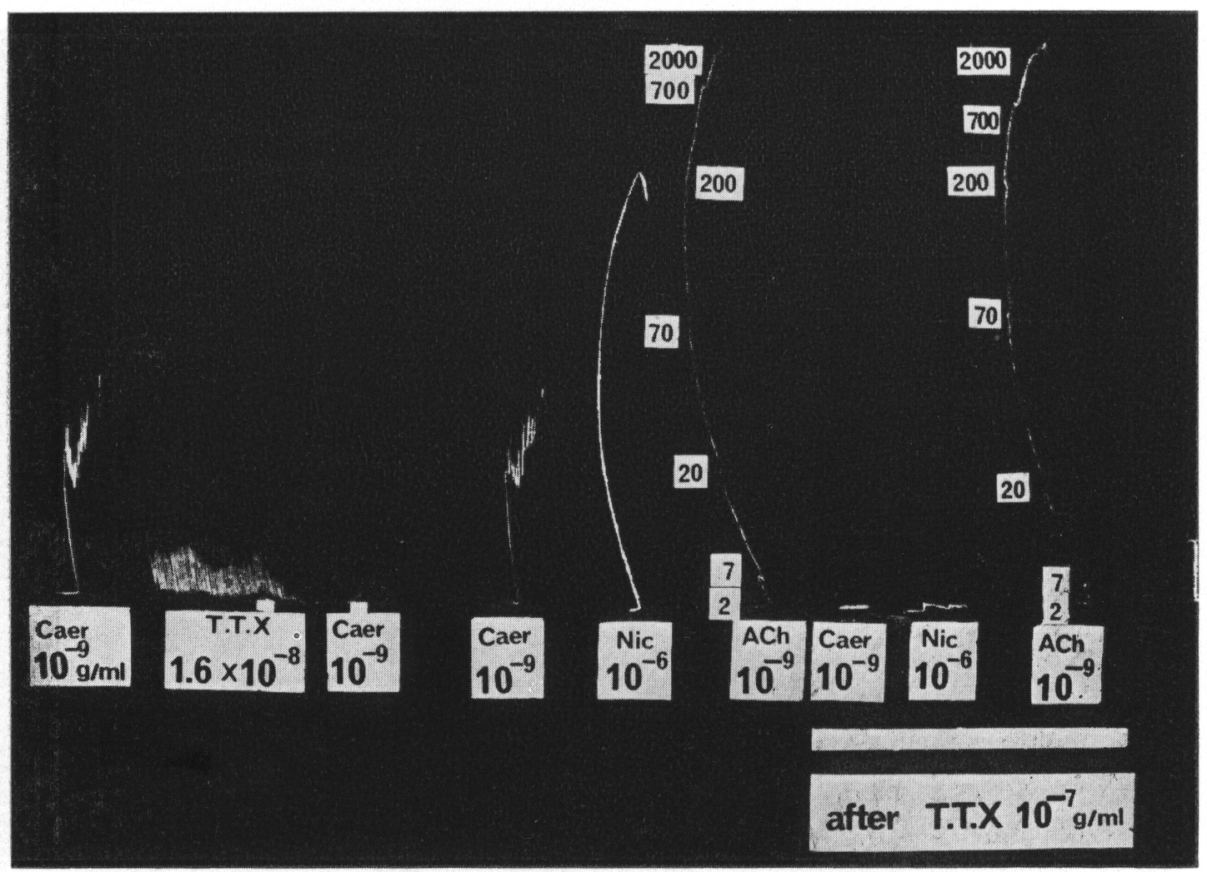

FIG. 7. Effects of tetrodotoxin on contraction of guinea-pig ileum produced by caerulein, $\mathrm{ACh}$, nicotine and the coaxial stimulation.

Caer : caerulein. ACh : acetylcholine. Nic : nicotine. T.T.X : tetrodotoxin.

Coaxial stimulation : $0.1 \mathrm{HZ}, 1 \mathrm{msec}, 20 \mathrm{~V}$. 


\section{Tetrodotoxin}

Tetrodotoxin $1.6 \times 10^{-8} \mathrm{~g} / \mathrm{ml}$ completely inhibited twitches of the coaxially stimulated ileum and the contraction by caerulein was inhibited by approx. $80 \%$. Tetrodotoxin $10^{-7}$ $\mathrm{g} / \mathrm{ml}$ completely inhibited the contraction by caerulein and almost completely inhibited the contraction by nicotine but had no effect on the contraction by acetylcholine (Fig. 7) (Table 2).

\section{Morphine}

Morphine $10^{-7} \mathrm{~g} / \mathrm{ml}$ showed a strong inhibitory tendency and morphine $10^{-6} \mathrm{~g} / \mathrm{ml}$ inhibited the contraction by caerulein almost completely, the contraction by nicotine by approx. $80 \%$, but had no effect on the contraction by acetylcholine (Fig. 8) (Table 2).

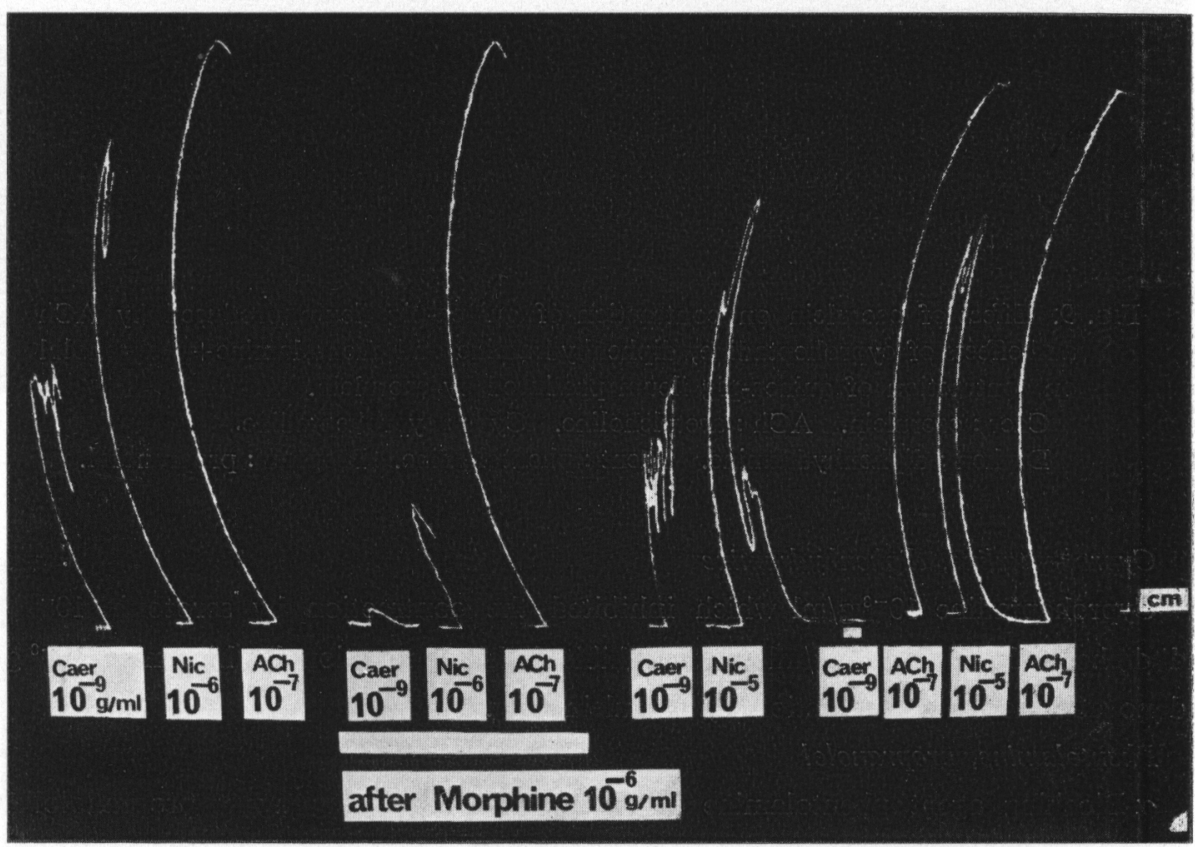

FIG. 8, Effects of morphine and nicotine on contraction of guinea-pig ileum produced by caerulein and $\mathrm{ACh}$.

Caer : caerulein. ACh : acetylcholine. Nic : nicotine.

\section{Nicotine}

When a high concentration $\left(10^{-5}-10^{-6} \mathrm{~g} / \mathrm{ml}\right)$ of nicotine was applied to the preparation, the transient contraction appeared but returned to the initial tone baseline after approx. $1 \mathrm{~min}$. Once returned to the baseline, the contraction by nicotine no longer appeared even when a high concentration of nicotine again was applied. The contraction by acetylcholine was hardly influenced in this state, however that by caerulein was completely inhibited (Fig. 8) (Table 2). 


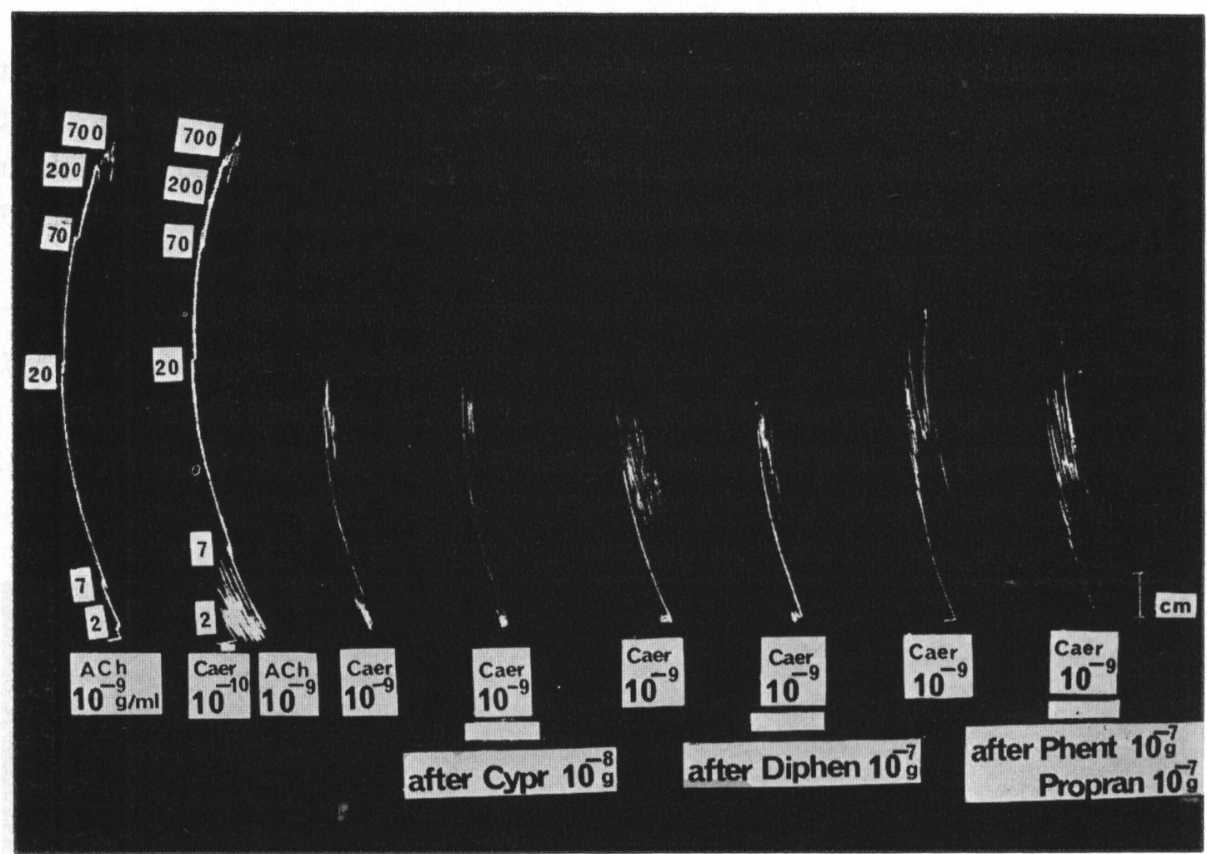

FIG. 9. Effect of caerulein on contraction of guinea-pig ileum produced by ACh and effects of cyproheptadine, diphenhydramine and phentolamine + propranolol on contraction of guinea-pig ileum produced by caerulein.

Caer : caerulein. ACh : acetylcholine. Cypr: cyproheptadine.

Diphen : diphenhydramine. Phent : phentolamine. Propran : propranolol.

\section{Cyproheptadine, diphenhydramine}

Cyproheptadine $10^{-8} \mathrm{~g} / \mathrm{ml}$ which inhibited the contraction by serotonin $10^{-6} \mathrm{~g} / \mathrm{ml}$ and diphenhydramine $10^{-7} \mathrm{~g} / \mathrm{ml}$ which inhibited the contraction by histamine $10^{-8} \mathrm{~g} / \mathrm{ml}$ had no effect on the contraction by caerulein (Fig. 9).

\section{Phentolamine, propranolol}

$\alpha$-Blocking agent phentolamine $10^{-7} \mathrm{~g} / \mathrm{ml}$ plus $\beta$-blocking agent propranolol $10^{-7}$ $\mathrm{g} / \mathrm{ml}$ had no effect on the contaction by caerulein (Fig. 9).

Effect of caerulein on twitches of the coaxially stimulated ileum

Potentiation of twitches of the coaxially stimulated ileum was observed at a dose of $5 \times 10^{-11} \mathrm{~g} / \mathrm{ml}$ of caerulein. Caerulein alone at this dose had no effect (Fig. 10).

Effect of caerulein on the contraction by acetylcholine

Caerulein $10^{-10} \mathrm{~g} / \mathrm{ml}$, which alone

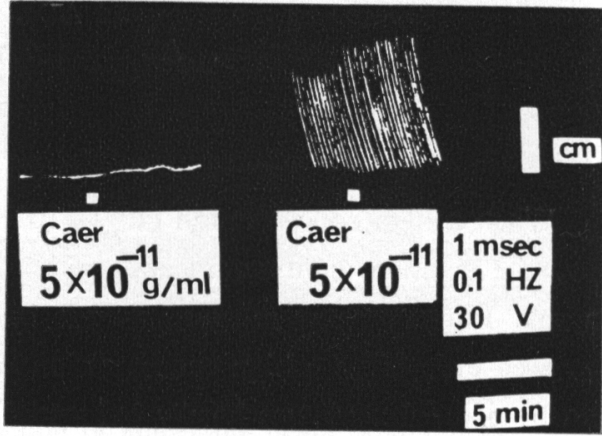

FIG. 10. Effect of caerulein on contraction of the coaxially stimulated guinea-pig ileum. Caer : caerulein. 
did not cause a strong contraction in the ileum, also did not potentiate the contraction by acetylcholine (Fig. 9).

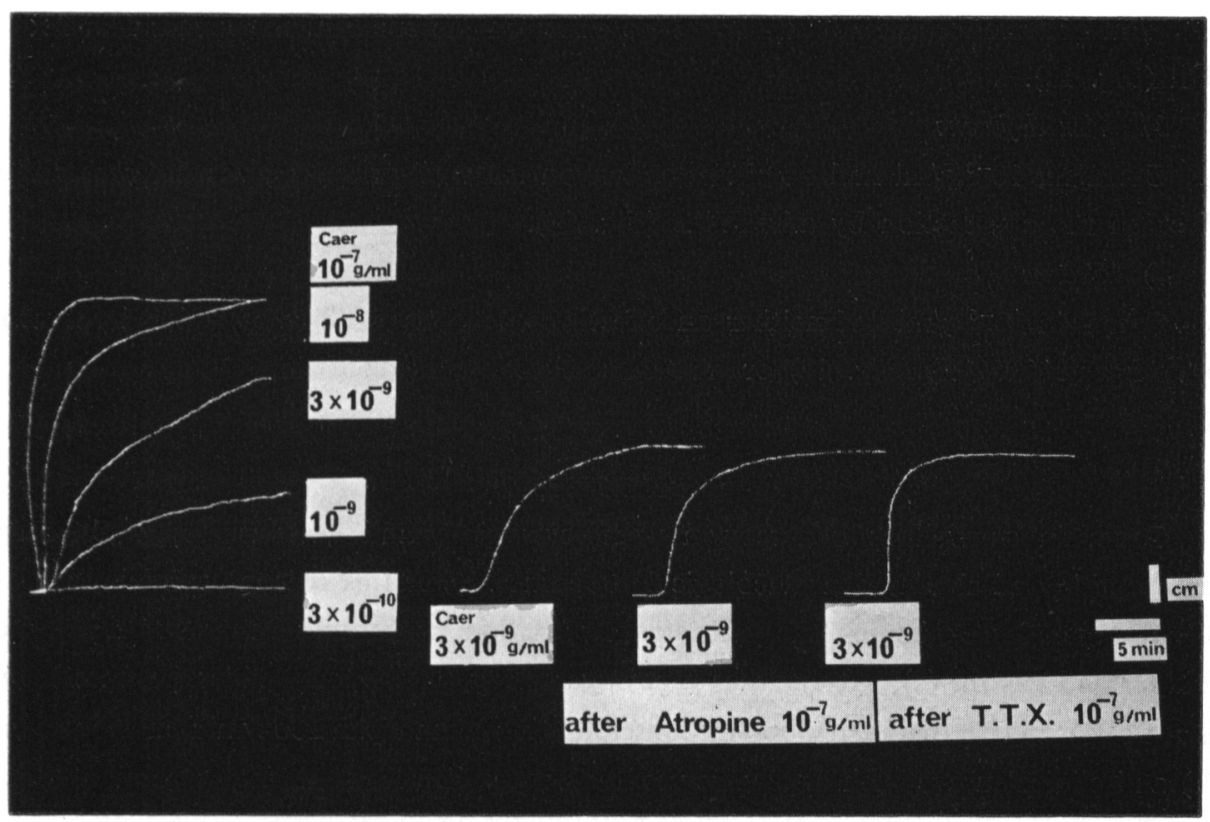

FIG. 11. Effects of atropine and tetrodotoxin on contraction of guinea-pig gallbladder produced by caerulein. Caer : caerulein. T.T.X : tetrodotoxin.

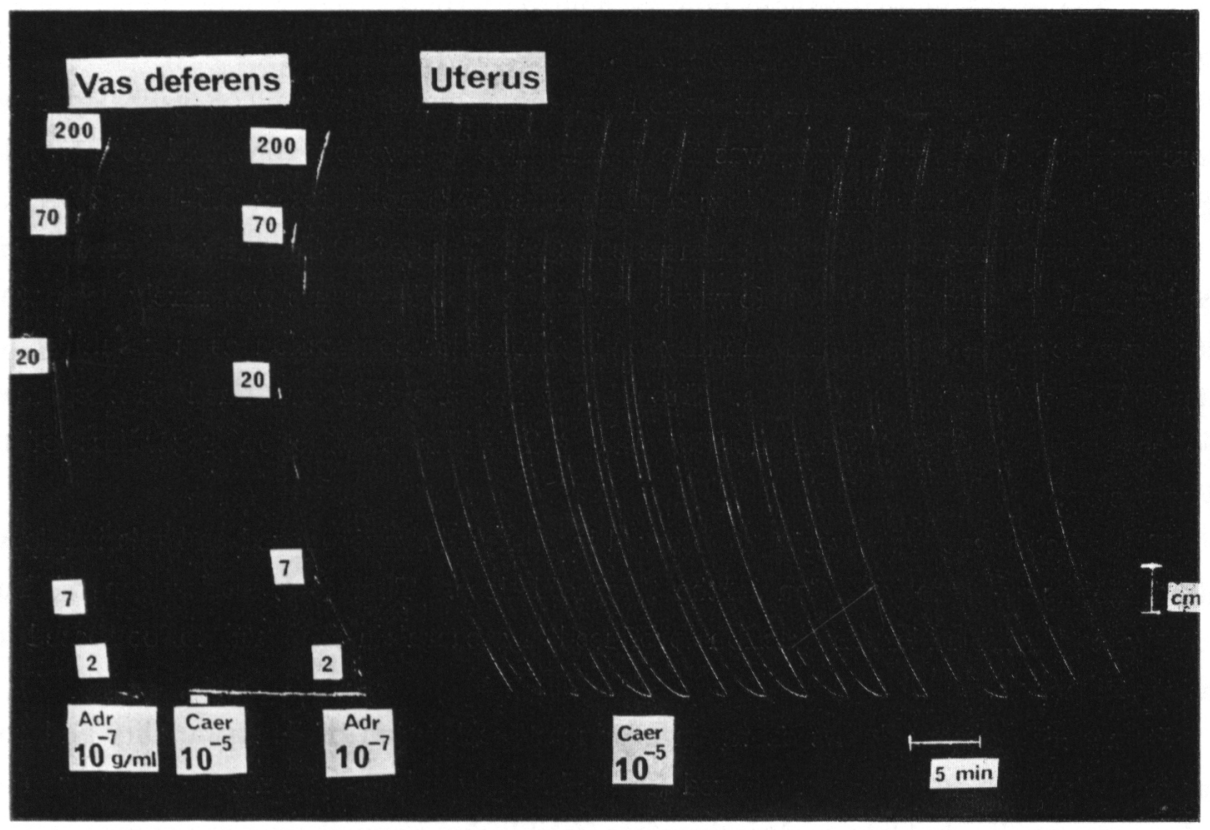

FIG. 12. Effects of caerulein on contraction of isolated guinea-pig vas deferens by adrenaline and on spontaneous motility of rat uterus (oestrous). 


\section{2) Gallbladder}

Caerulein produced a contraction at a dose of $10^{-10}-3 \times 10^{-10} \mathrm{~g} / \mathrm{ml}$. Tachyphylaxis and sensitization were not present but dose-response relationship was observed. Atropine $10^{-7} \mathrm{~g} / \mathrm{ml}$ or tetrodotoxin $10^{-7} \mathrm{~g} / \mathrm{ml}$ had no effect on the contraction by caerulein $3 \times 10^{-9}$ $\mathrm{g} / \mathrm{ml}$ (Fig. 11).

3) Vas deferens

Caerulein $10^{-5} \mathrm{~g} / \mathrm{ml}$ had no direct action on isolated guinea-pig vas deferens and no effect on the contraction by adrenaline (Fig. 12).

4) Uterus

Caerulein $10^{-5} \mathrm{~g} / \mathrm{ml}$ had neither an effect spontaneous motility of isolated rat uterus (oestrus and diestrus) (Fig. 12) or on the contraction by oxytocin.

\section{DISCUSSION}

Caerulein as well as pancreozymin-cholecystokinin and gastrins has a C-terminal pentapeptide and similar pharmacological properties. For this reason caerulein is a useful substance for explaining the mechanism of action concerning pancreozymin-cholecystokinin and gastrin (2). It also has a stronger effect on the gallbladder (in anesthetized gu inea-pigs) and the jejunal loop (in conscious dogs) than pancreozymin-cholecystokinin (11) and clinical usage such as cholecystography etc. (12) is attracting general attention.

The effect of caerulein on motility of the intestinal tract and the gallbladder in situ has been reported in dogs (2-4). In the present paper, caerulein produced an accerelation of motility of rabbit ileum, that is, increase of the amplitude and the tone of peristaltic waves. The intravenous threshold dose of approx. $10 \mathrm{ng} / \mathrm{kg}$ was a little higher than in dogs (the threshold dose: $1-5 \mathrm{ng} / \mathrm{kg}$ ) $(2,3)$.

Caerulein showed a stimulant action on rabbit gallbladder. The gallbaldder was more sensitive to caerulein than was the ileum. The intravenous threshold dose was 1-5 $\mathrm{ng} / \mathrm{kg}$ and much higher than in dogs and humans (threshold doses: $0.5-1 \mathrm{ng} / \mathrm{kg}$ ) (2).

Caerulein caused hypotension in most cases at a dose of $10 \mathrm{ng} / \mathrm{kg}$ i.v. in parallel with acceleration of ileum motility. However, change in blood pressure was rarely seen while there was acceleration of ileum motility and gallbladder contraction as a result of s.c. injection of $0.5 \mu \mathrm{g} / \mathrm{kg}$ of caerulein. Such being the case it is presumed that caerulein produces acceleration of ileum motility and gallbladder contraction regardless of the hypotension.

The effect of caerulein was also observed in bilaterally vagotomized and splanchnicotomized rabbits with no variation in the threshold dose. Therefore, acceleration of ileum motility and gallbladder contraction produced by caerulein appears to be based on peripheral action.

It was also observed that caerulein produces acceleration of ileum motility and contraction of gallbladder in reserpinized and bilaterally adrenalectomized rabbit with no variation in the threshold dose. It is therefore feasible that sympathetic nerve endings are not involved in ileum motility acceleration and gallbladder contraction produced by caerulein. 
Small intestine transit test (mouse): Carbon powder had already passed from the stomach to the intestine $10 \mathrm{~min}$ after oral administration (transit rate: approx. $20 \%$ ), at which time caerulein accelerated the transit. Coupled with the result of ileum motility acceleration, it is considered that caerulein has an accelerating action on co-ordinated propulsion rather than simply inducing contraction of the intestinal tract as previously proposed $(3,5)$.

When caerulein was given $10 \mathrm{~min}$ before carbon powder, accelerated transit was observed at small doses while with large doses transit was inhibited. It is established that caerulein has an accelerating action on stomach motility, however Messini et al. (13) reported discontinued flow of stomach contents and Bertaccini et al. (2), Mantovani et al. (14) described a spasmodic action on the pyloric sphincter. Transit inhibition at large doses is therefore considered to be an inhibition of transit from the stomach to the intestine by pyloric spasm. The threshold dose is estimated to be higher than that for acceleration of intestinal motility.

Mechanism of action of isolated ileum and gallbladder: Caerulein produced an acceleration of rhythmic movement after contraction of isolated guinea-pig ileum. Tachyphylaxis and sensitization were not present but dose-response relationship was observed. The acceleration of rhythmic movement could be suppressed to some degree by reducing the temperature in the organ bath $\left(26 \pm 1{ }^{\circ} \mathrm{C}\right)$. Therefore, it appears just as feasible to use isolated guinea-pig ileum for quantitative bioassay of caerulein as the isolated rabbit colon used by Mantovani and Impicciatore (6).

With reference to the mechanism of action on isolated guinea-pig ileum, Del Tacca et al. (7) suggested that caerulein acts directly on either the nerve endings or the muscle cells because the contraction was not inhibited completely by tetrodotoxin.

In our experiments, (a) contraction with caerulein was fully inhibited by tetrodotoxin and nicotine, giving the impression that the action was mediated through the nerve. (b) the contraction was inhibited by atropine and potentiated by eserine. (c) the contraction was almost completely inhibited by morphine which inhibits liberation of acetylcholine from cholinergic nerve endings. (d) recently Takagi and Takayanagi (15) reported that twitches at $0.1 \mathrm{HZ}$ are the result of stimulation of the cholinergic nerve and not direct stimulation of the smooth muscles. Potentiation of twitches of the coaxially stimulated ileum by caerulein was observed, therefore the action appeared to be concerned with the cholinergic nerve. (e) since the contraction was slightly inhibited by hexamethonium, the greater part of action of caerulein did not appear to be concerned with nicotinic receptor. (f) the fact that there was no potentiation of contraction by acetylcholine suggests that there may be no anticholinesterase activity.

From the above results, it can be considered that caerulein acts on non-nicotinic receptor and accelerates liberation of acetylcholine from cholinergic nerve endings. It is also considered that caerulein acts, at least in part, on the atropine-resistant nervous element as it was not completely inhibited by atropine in larger doses. Histamine and serotonin do not appear to be the transmitter responsible for the atropine resistant contrac- 
tion. This is in accordance with the observation of Del Tacca et al. (7). Similar to the in situ result (rabbit), sympathetic nerve endings do not appear to be involved in the action of caerulein.

Caerulein showed a strong excitatory effect on isolated guinea-pig gallbladder at low doses almost equal to the threshold dose of isolated ileum contraction. This preparation appeared to be the best for quantitative bioassay of caerulein, with the mechanism appearing to have direct action on the gallbladder smooth muscle as the contraction was not inhibited by atropine and tetrodotoxin as reported previously (2).

Vas deferens and uterus: Caerulein had no direct action on isolated guinea-pig vas deferens, no effect on the contraction by adrenaline, no direct action on isolated rat uterus and no effect on the contraction by oxytocin, therefore the action of this decapeptide caerulein is considered to be of organ specificity.

Acknowledgement: The authors would like to thank Associate Professor Dr. I. Takayanagi, Department of Chemical Pharmacology, Faculty of Pharmaceutical Sciences, University of Tokyo, for advice and criticism.

\section{REFERENCES}

1) Anastasi, A., Erspamer, V. and Endean, R.: Experientia 23, 699 (1967)

2) Bertaccini, G., De Caro, G., Endean, R., Erspamer, V. and impicciatore, M.: $B r . J$. Pharmacol. Chemother. 34, 291 (1968)

3) Mantovani, P. and Bertaccini, G.: Archs int. Pharmacodyn. Thér. 193, 362 (1971)

4) Mantovani, P. Puccinin, G.L. And Bertaccini, G.: Pharmacol. Res. Commun. 1, 172 (1969)

5) Frigo, G.M., Lecchini, S., Falaschi, C., Del Tacca, M. and Crema, A.: Arch. Phamakol. 268, 44 (1971)

6) Mantovani, P. And Impicciatore, M.: Arch. Pharmakol. 271, 330 (1971)

7) Del Tacca, M., Soldani, G. and Crema, A.: Agents and Actions 1, 176 (1970)

8) Paton, W.D.M.: Br. J. Pharmacol. Chemother. 12, 119 (1957)

9) Takagi, K. and Takayanagi, I.: Japan. J. Pharmacol. 16, 211 (1966)

10) Kumagai, H., Ebashi, S. and Takeda, F.: Japan. J. Pharmacol. 2, 65 (1952)

11) Vagne, M. And Grossman, M.I.: Am. J. Physiol. 215, 881 (1968)

12) Bertaccini, G., Braibanti, T. AND Uva, E.: Gastroenterology 56, 862 (1969)

13) Messini, M. and Grossi, F.: $X V^{e}$ Giornate Mediche di Montecatini. 9-10 maggio (1970)

14) Mantovani, P., Piccinin, G.L. and Ugolotti Adorni Mc: Archs int. Pharmacodyn. Thér. 189, 319 (1971)

15) Takagi, K. and Takayanagi, I.: Japan. J. Pharmacol. 22, 33 (1972) 